16. Дмитриева Е.Н. Информационно-смысловой подход в профессиональной подготовке учителя (теоретико-методологические основы): монография. Нижний Новгород: НГЛУ им. Н.А. Добролюбова, 2003. 183 c.

17. Бондаревская Е.В. Смыслы и стратегии личностно ориентированного образования // Педагогика. 2001. № 1. C. 17-24.

18. Абакумова И.В., Кагермазова Л.Ц. Смысловые коммуникации в учебном процессе: теория и технологии направленной трансляции смыслов в обучении: монография. М.: Илекса; Нальчик: Издательство М. и В. Котляровых (Полиграфсервис и Т), 2008. $232 \mathrm{c}$.

19. Марьина Т.А., Воробьева К.И. Смысл профессии и профессиональной деятельности в структуре смысложизненных ориентаций личности // Научнотехническое и экономическое сотрудничество стран АТР в XXI веке. 2013. Т. 2. С. 250-254.

\title{
STUDENTS' PROFESSIONAL IDENTITY DEVELOPMENT THROUGH A SENSE-MAKING ACTIVITY
}

(C) 2017

\author{
Karpova Olga Leonidovna, doctor of pedagogical sciences, \\ professor of Humanities, Natural Sciences and Mathematical Disciplines Department \\ Ural Institute of Social Sciences and Economics (Academy of Labour and Social Relations branch) \\ (Chelyabinsk, Russian Federation) \\ Nain Albert Yakovlevich, doctor of pedagogical sciences, professor, head of Pedagogy Department \\ Ural State University of Physical Culture (Chelyabinsk, Russian Federation)
}

\begin{abstract}
The authors of the paper have identified key challenges that make the process of students' professional identity development difficult in modern society. The research is based on the study of needs of society, regulatory framework, as well as the authors' own teaching experience. The authors found controversies that led to the scientific problem of students' professional identity development through a sense-making activity. The paper contains an extensive theoretical basis that helps to identify the essence of students' sense-making activity as a psychological and pedagogical problem. The authors analyze recent researches related to students' semantic education development. They develop and illustrate the structure of students' sense-making activity, which includes the following substantial components: identity, cognitive, motivational-semantic and value-regulatory components. The components of the developed structure perform determination and regulation functions of professional activities, development, selfdevelopment and self-identity as the basis for students' professional identity development. The paper contains criteria for sense-making activity structure assessment: passion, professional activities; breadth of interests; professional identity; self-conscious and finding the meanings of professional activity in the system of life goals, plans and programs. The authors formulate pedagogical conditions promoting effective professional identity development of university students through a sense-making activity.

Keywords: development; professional identity; students; meanings; framework; sense-making activity; structure; substantial components; criteria; pedagogical conditions; component identity; cognitive component; motivationalsemantic component; value-regulatory component.
\end{abstract}

УДК 378

\section{ТЕОРЕТИЧЕСКАЯ МОДЕЛЬ ПЕДАГОГИЧЕСКОЙ СИСТЕМЫ ФОРМИРОВАНИЯ ИНФОРМАЦИОННО-КОММУНИКАТИВНОЙ КОМПЕТЕНТНОСТИ СТУДЕНТОВ - БУДУЩИХ СПЕЦИАЛИСТОВ ПО СВЯЗЯМ С ОБЩЕСТВЕННОСТЬЮ}

(C) 2017

\author{
Михелькевич Валентин Николаевич, доктор технических наук, \\ профессор кафедры психологии и педагогики
}

Мякинькова Светлана Николаевна, преподаватель кафедры психологии и педагогики Самарский государственньй технический университет (2. Самара, Российская Федераџия)

\begin{abstract}
Аннотащия. В статье рассматривается теоретическая модель педагогической системы формирования информационно-коммуникативной компетентности студентов - будущих специалистов по связям с общественностью. Данная компетентность формируется в течение всей сознательной жизни человека и обеспечивает эффективное межличностное и социальное взаимодействие с использованием полученной и переработанной в соответствии с профессиональными задачами информации. В работе представлена авторская трактовка определения понятия «информационно-коммуникативная компетентность специалиста по связям с общественностью». Описаны теоретико-методологические основания и квалиметрические условия, с учетом которых была синтезирована теоретическая модель педагогической системы формирования информационнокоммуникативной компетентности студентов бакалавриата по направлению «Реклама и связи с общественностью» (профиль «Связи с общественностью»). Показана актуальность, теоретическая значимость и практическая ценность рассматриваемой теоретической модели педагогической системы формирования информационно-коммуникативной компетентности студентов - будущих специалистов по связям с общественностью с точки зрения использования ее как методологической основы для проведения педагогического эксперимента. Приведены данные о практической реализации теоретической модели педагогической системы:
\end{abstract}


разработана система практических занятий по базовым дисциплинам учебного плана; проведена систематизация и отбор существующих педагогических технологий; подготовлены учебно-методические пособия, отражающие в своем содержании цели педагогической системы, а также способы их достижения; разработана и апробирована в учебном процессе методика педагогического эксперимента. Предложенный критериальнодиагностический аппарат позволил сделать предварительную оценку полученных результатов и провести коррекцию разработанной системы для обеспечения наибольшей ее эффективности.

Ключевые слова: теоретическая модель; педагогическая система; информационно-коммуникативная компетентность; специалист по связям с общественностью; система практических занятий; учебно-методические пособия; методика педагогического эксперимента; критериально-диагностический аппарат; коррекция системы.

До недавнего времени России в большей степени был присущ PR политический и PR в сфере шоубизнеса, однако ситуация в последние годы меняется, и спрос на услуги специалистов по связям с общественностью в бизнес-секторе уверенно растет. Сейчас услугами пиарщиков пользуется большинство крупных российских и международных компаний, работающих на отечественном рынке [1]. Специалисты по связям с общественностью работают в государственных учреждениях, транснациональных корпорациях, в учреждениях культуры, в крупных транспортных предприятиях, в учреждениях связи и телекоммуникаций.

Как следует из Федерального государственного образовательного стандарта третьего поколения подготовки бакалавров этого направления [2], а также из наших ранее опубликованных работ [3-6], доминирующей целью освоения студентами бакалавриата основных образовательных программ является формирование у них информационно-коммуникативной компетентности (ИКК). Основой ИКК являются так называемые ключевые компетенции, формируемые в течение всей жизни, всех этапов образовательного процесса. Понятие информационно-коммуникативной компетентности не является в научнопедагогической литературе новым, однако до сих пор четкого определения его не было дано [7-12]. В данной работе под термином «информационнокоммуникативная компетентность» специалиста по связям с общественностью мы понимаем интегративную характеристику личностных качеств индивидуума, способного не только овладеть необходимыми профессиональными знаниями, но и умеющего эффективно их использовать и в стандартных, и в непривычных профессиональных ситуациях; знающего разнообразные приемы поиска информации, ее оценивания и преобразования с целью использования в профессиональной деятельности с сочетанием индивидуальных и коллективных форм взаимодействия.

Высокий уровень сформированности ИКК специалиста по связям с общественностью позволяет оперативно организовать поиск, переработку и систематизацию необходимой информации для логически корректного, аргументированного изложения своей позиции в предстоящем общении и с представителями компании-работодателя, и с представителями общественности.

Для развития и формирования у студентов ИКК необходимо разработать и практически реализовать целостную педагогическую систему. Работу по проектированию и реализации такой системы целесообразно начинать с создания теоретической модели, поскольку моделирование позволяет еще на стадии проектирования выявить и исследовать дидактические и организационно-методические характеристики и свойства, психолого-педагогические возможности, ценности и недостатки, оценить значимость каждого из звеньев системы в совокупном результате ее функционирования [13].

В отечественной и зарубежной педагогической литературе содержится ряд определений понятия «моделирование», авторы которых трактуют его либо как метод исследования объектов на моделях аналогов определенного фрагмента природной или социальной действительности, либо как процесс построения и изучения модели реально существующих предметов, объектов и явлений. В самом общем виде можно сказать, что педагогическое моделирование это разработка и создание формальной модели педагогического процесса или его составляющих, отражающей основные идеи, методы, формы, средства, приемы и технологические решения, которые подлежат в дальнейшем экспериментальному изучению в условиях реального педагогического процесса.

Моделирование по определению осуществляется с помощью модели. Модель (от лат. modulus - мера, образец) - это упрощенный мысленный или знаковый образ какого-то объекта или системы объектов, используемый в качестве их «заменителя» и средства оперирования. По определению В.В. Краевского, модель - это результат абстрактного обобщения практического опыта, а не прямой результат эксперимента [14]. А.И. Богатырев образно определяет модель как искусственно созданный объект в виде схемы, физических конструкций, знаковых форм или формул, которые, будучи тождественными исследуемому объекту или явлению, отражают и воспроизводят в более простом и обобщенном виде структуру, свойства, взаимосвязи и отношения между элементами [15].

Интересное философско-методологическое определение дано Г.П. Щедровицким, который называет моделью «прототип ориентированного в будущее действия», считая, что «модель - это высокоспециализированные части нашего технологического оснащения, специфические функции которых состоят в создании будущего... Модель не просто некоторая сущность, а скорее способ действия, который представляет эту сущность. В этом смысле модели - это воплощение целей и в то же время инструмент воплощения этих целей. Модель одновременно учитывает цель и гарантирует ее реализацию [16].

При разработке теоретической модели системы формирования ИКК мы учитывали следующие условия и положения: 
Михелькевич В.Н., Мякинькова С.Н.

- между моделью и оригиналом должны быть соотношения сходства, соответствия адекватности, форма которых явно выражена и зафиксирована;

- модель в процессе научного познания при соблюдении условия репрезентативности является заместителем изучаемой педагогической системы;

- изучение модели системы позволяет получить информацию об оригинале (условие экстраполяции).

На основе представленных выше теоретико-методологических оснований авторами была синтезирована теоретическая модель педагогической системы формирования информационно-коммуникативной компетентности студентов - будущих специалистов по связям с общественностью, представленная на рис. 1. Из рисунка видно, что педагогическая система формирования информационно-коммуникативной компетентности (ИКК) в своей структуре содержит десять взаимосвязанных (по преемственнологической последовательности проектирования и практической реализации) блоков, начиная с блока целеполагания (1) и заканчивая блоком 8, отражающим результат функционирования системы. При этом каждый блок имеет свою локальную цель, функцию, ценность.

Первым, исходным звеном модели системы является звено целеполагания (1). Причем целеполагание здесь отражает, с одной стороны, потребности общества в специалистах по связям с общественностью, обладающих ИКК, а с другой стороны, как ожидаемый результат функционирования педагогической системы, - формирование у студентов ИКК.

Звено 2 - обоснование и конкретизация целевых индикаторов. В этом звене разрабатываются содержание, состав и структура ИКК, научно обосновываются требования К уровню сформированности ИКК и ее компонентов.

Следующим звеном теоретической модели системы (3) является информационно-дидактическая база формирования у студентов - будущих специалистов по связям с общественностью ИКК в процессе освоения ими основных образовательных программ по профилю бакалаврской подготовки. Доминирующими компонентами информационно-дидактической базы, в процессе освоения которой у студентов развивается и формируется ИКК, являются:

- содержание базовых дисциплин учебного плана подготовки бакалавров по направлению «Реклама и связи с общественностью», профиля «Связи с общественностью»;

- содержание практических занятий и производственных практик студентов;

- специализированные учебно-методические пособия, отражающие специфику профиля подготовки бакалавров.

Звено 4 модели системы - педагогическая технология формирования у студентов ИКК. В этом звене рассматриваются и теоретически обосновываются методы, способы, приемы, формы и средства обучения, обеспечивающие в процессе освоения студентами учебного материала оптимальное (при максимальной результативности и минимальном расходе ресурсов) развитие и формирование у обучающихся ИКК. При этом на разных временных этапах мультидисциплинарной профессиональной подготовки селективно используются разнообразные как традиционные, так и инновационные образовательные технологии. Среди наиболее эффективных и широко практикуемых технологий обучения - диалоговые технологии, деловые и ролевые игры, метод анализа конкретных ситуаций (case study) и другие.

Следующее, пятое звено модели системы - это критериально-диагностический аппарат. В этом звене представлены критерии и показатели сформированности ИКК, средства контроля и оценивания ИКК, методики проведения констатирующего и формирующего экспериментов.

Звено 7 модели системы «Процедуры контроля» отражает методику процесса проведения педагогического эксперимента по измерению и оценке уровней сформированности у студентов ИКК. Естественно, что в результате выполнения этих процедур могут иметь место два альтернативных варианта:

- если результаты эксперимента соответствуют установленным требованиям к уровням сформированности ИКК (вариант «Да»), то результат признается положительным (звено 8);

- если уровень сформированности того или иного показателя у студента окажется ниже установленного порогового (вариант «Нет»), то такой студент должен произвести самокоррекцию своей учебной деятельности (звено 9), дополнительно поработать для достижения требуемой цели.

В случае же отклонения от нормы значительного числа студентов ведущий преподаватель должен проанализировать, не является ли это следствием недостаточной эффективности использования той или иной педагогической технологии либо недостаточности организационно-методического обеспечения, а в случае обнаружения такого недостатка произвести соответствующую коррекцию учебного процесса (звено 10).

Представленная теоретическая модель педагогической системы формирования информационнокоммуникативной компетентности у студентов - будущих специалистов по связям с общественностью выступила методологической основой создания информационно-дидактической базы: была разработана система практических занятий по базовым дисциплинам учебного плана, а также отобраны наиболее перспективные с точки зрения формирования ИКК педагогические технологии, подготовлены учебнометодические пособия, отражающие в своем содержании цели педагогической системы, а также способы их достижения. Кроме того, была разработана и апробирована в учебном процессе методика педагогического эксперимента по формированию ИКК. Предложенный критериально-диагностический аппарат позволил сделать предварительную оценку полученных результатов и провести коррекцию разработанной системы для обеспечения наибольшей эффективности ее реализации. 


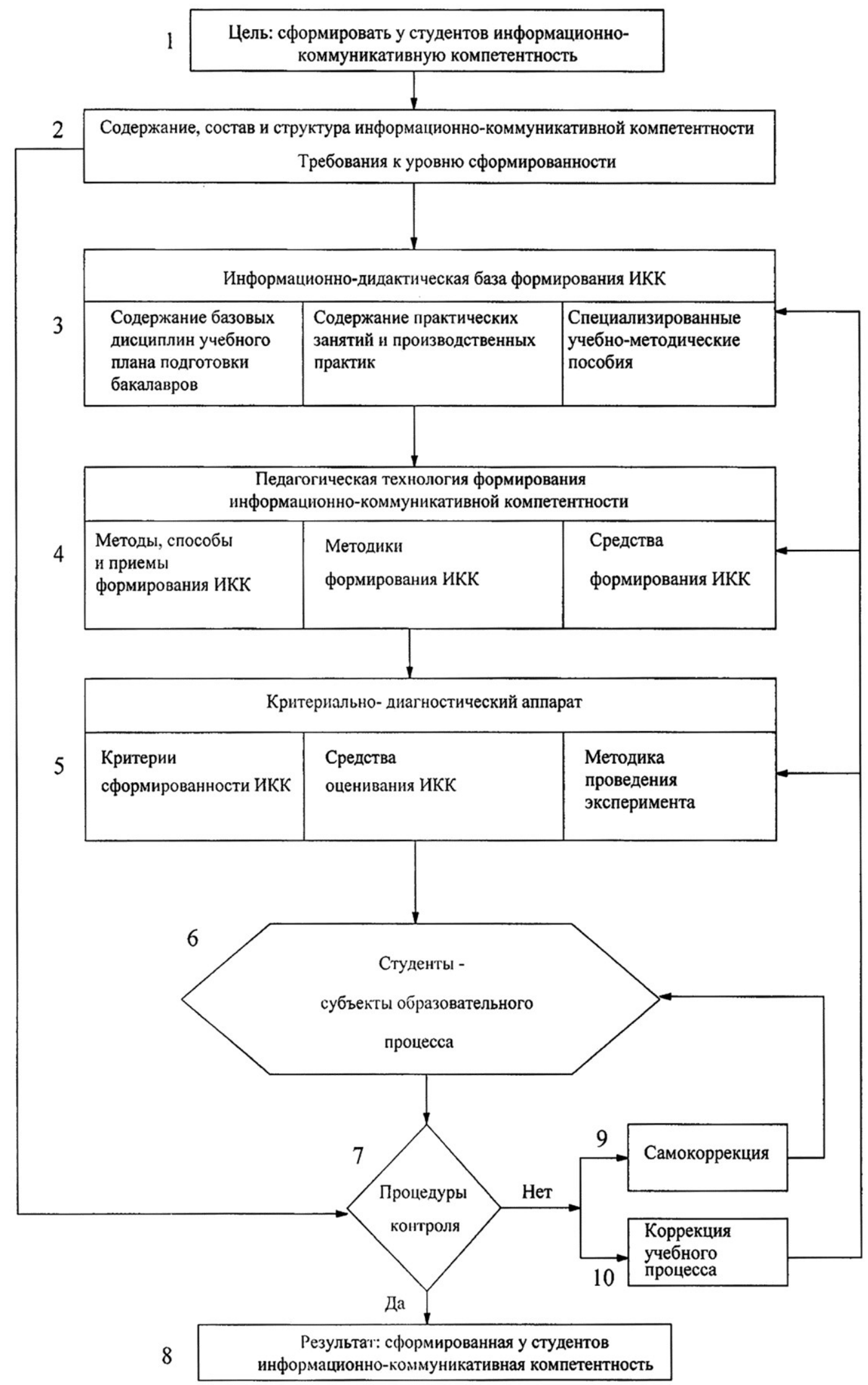

Рисунок 1 - Теоретическая модель педагогической системы формирования информационно-коммуникативной компетентности студентов - будущих специалистов по связям с общественностью

\section{СПИСОК ЛИТЕРАТУРЫ:}

1. Чумиков А.Н., Бочаров М.П., Самойленко С.А. Связи с общественностью. Теория и практика. М.: «Дело» АНФ, 2016. 520 c.
2. Федеральный государственный образовательный стандарт высшего образования по направлению подготовки 42.03.01 «Реклама и связи с общественностью» (уровень бакалавриата) // http://fgosvo.ru/ uploadfiles/fgosvob/420301.pdf. 
Михелькевич В.Н., Мякинькова С.Н.

3. Кравцов П.Г., Михелькевич В.Н. Традиции и инновации в оценивании результатов функционально-ориентированной подготовки выпускников технических вузов // Новая стратегия оценивания учебной деятельности: сб. науч. статей. Самара: СамГТУ АСИ, 2016. С. 343-348.

4. Михелькевич В.Н., Попов Д.В., Антонов Г.М. Деятельностный подход к формированию у курсантов личностных профессионально-значимых качеств // Правовое и духовно-нравственное воспитание российского офицерства: мат-лы всерос. науч.-практ. конф. Самара: Самарский юридический институт, 2015. C. $160-171$.

5. Мякинькова С.Н. Информационно-коммуникативная компетентность и ее роль в профессиональнотворческом развитии студентов // Актуальные проблемы гуманитарных и социально-экономических наук: сб. мат-лов $\mathrm{X}$ международной научнопрактической конф. / под ред. А.В. Немчининова. М.: Изд-во «Перо»; Вольск: Тип. ВВИМО, 2016. Ч. 3. Актуальные проблемы психологии и педагогики. В 2 кн. Кн. 2. С. 40-47.

6. Мякинькова С.Н. Структура информационнокоммуникативной компетентности специалистов технического профиля // Актуальные проблемы развития высшего и среднего образования на современном этапе: мат-лы VII всерос. науч.-практ. конф. ученых и педагогов-практиков / отв. ред. В.М. Медведев. Самара: Изд-во СНЦ РАН, 2012. C. $239-241$.

7. Арутюнова Н.В. Формирование информационно-коммуникативной компетентности студентов в системе университетской подготовки к педагогической деятельности: по направлению подготовки 020100 «Химия»: автореф. дис. ... канд. пед. наук. Ставрополь, $2011.25 \mathrm{c}$.

\section{PEDAGOGICAL SYSTEM \\ OF INFORMATION-COMMUNICATIVE COMPETENCE DEVELOPMENT OF STUDENTS - PROSPECTIVE PUBLIC RELATIONS EXPERTS} (C) 2017
8. Бочарова Л.В. Формирование информационнокоммуникативной компетентности социального педагога на основе учебно-методического комплекса «Компьютерное издательство»: автореф. дис. ... канд. пед. наук. Курск, 2006. 22 с.

9. Вишнякова А.В. Образовательная среда как условие формирования информационно-коммуникативной компетентности учащихся: дис. ... канд. пед. наук. Оренбург, 2002. 172 с.

10. Поливода И.М. Информационно-коммуникативная культура как источник развития профессионального мышления студентов технического университета: автореф. дис. ... канд. пед. наук. Ростов-наДону, 2006. 23 с.

11. Софинская Е.Н. Формирование информационно-коммуникативной компетенции у будущих специалистов социальной работы в условиях вуза: автореф. дис. ... канд. пед. наук. М., 2011. 27 с.

12. Федотова Е.Ю. Формирование информационно-коммуникативной компетентности учащихся в процессе продуктивной учебно-познавательной деятельности: автореф. дис. ... канд. пед. наук. СПб., 2009. $24 \mathrm{c}$.

13. Галицков С.Я., Михелькевич В.Н., Назаров М.А., Болховецкий А.С. Моделирование как метод формирования образного восприятия // Актуальные проблемы естественно-научного и математического образования: мат-лы междунар. науч.-практ. конф. Самара: Изд-во СГСПУ, 2016. С. 14-17.

14. Краевский В.В. Методология для педагога: теория и практика. Волгоград: Перемена, 2001. 324 с.

15. Азимов А.Г., Щукин А.Н. Новый словарь методических терминов и понятий (теория и практика обучения языкам). М.: ИКАР, 2009. 448 с.

16. Щедровицкий Г.П. Система педагогических исследований. Педагогика и логика. М.: Касталь, 1993. $412 \mathrm{c}$.

Mikhelkevich Valentin Nicolaevich, doctor of technical sciences, professor of Psychology and Pedagogy Department

Myakinkova Svetlana Nikolaevna, lecturer of Psychology and Pedagogy Department Samara State Technical University (Samara, Russian Federation)

Abstract. The paper discusses a pedagogical system of information-communicative competence development of students - prospective public relations experts. This competence is formed throughout the conscious human life and provides effective interpersonal and social interaction using obtained and processed information in accordance with professional tasks. The paper presents the authors' definition of «information-communicative competence of a public relations specialist». The authors describe theoretical and methodological foundations and their qualitative conditions and synthesize a pedagogical system of information-communicative competence development of undergraduate students majoring in advertising and public relations. The authors think that the theoretical model of this system is urgent, significant and has a practical value from the point of view of its use as a methodological basis for pedagogical experiment. The authors present the results of the practical implementation of this theoretical model: a system of designed practical training in basic subjects of the curriculum; systematization and selection of existing educational technologies; training manuals, reflecting the targets of the educational system as well as the means of achieving them; a developed and tested methodology of the pedagogical experiment. The proposed criterion-diagnostic apparatus allowed the authors to make a preliminary assessment of the results and carry out the correction of the developed system to ensure maximum efficiency.

Keywords: theoretical model; educational system; information-communicative competence; public relations specialist; practical training system; teaching aids; method of pedagogical experiment; criterion-diagnostic apparatus; correction system. 